\title{
NUTRITIONAL OEDEMA IN CHILDREN IN EGYPT
}

\author{
BY
}

H. SHUKRY, M.R.C.P., M. A. MAHDI, M.Sc., B.Pharm., and A. A. EL GHOLMY, M.D.

(From the Paediatric Department of the Faculty of Medicine, Cairo.)

Oedema developing in the course of gastro-intestinal disorders of infancy has been noted in America by Maver (1920) and in Egypt by Shawki. It was of the same character as that which developed in adults during times of war and famine, as in Poland during the Great War, when the food available was of low caloric value (1200-1400 cal. per day) and no meat was obtained for months. The oedema, though resembling that of kidney disease, was not associated with any renal damage. Eighteen cases of gastro-intestinal disorder with oedema have been collected. All had previously been submitted to a prolonged period of starvation on medical or lay advice before attending the hospital because of some gastro-intestinal trouble and a variable fever. Food had been restricted to anisi or karaway and boiled barley or rice water. After a period varying from three days to two months, with an average of three weeks, during which the patients lost considerable weight and became pale and flabby, oedema appeared first in the eyelids, then in the hands and legs and lastly in the peritoneal cavity as ascites. No cardiac or renal disease was found to account for the oedema. The blood and oedema fluid of these cases were examined for their protein, chlorides, cholesterol and calcium content and the blood picture noted. The results are shown in the table.

The table shows certain features which will be dealt with more in detail later. In all except three cases the total serum protein was 4.5 per cent. or less, reaching the ' critical level' as in experimental oedema (Weech, Snelling and Goettsch, 1933). The reduction was mostly in the albumin fraction. The chlorides, instead of being only $50 \mathrm{mgm}$. per cent. higher in the cellular spaces, showed an increase of at least $120 \mathrm{mgm}$. per cent. and reached as much as 482 mgm. per cent. difference between the blood and oedema fluids in one of the cases. All cases showed a severe hypochromic anaemia with a low reticulocyte count. The cholesterol content of the blood was always low. The anaemia and general weakness tended to persist after the oedema had disappeared. From the table two facts stand out : (1) the almost constantly present hypoproteinaemia ; and (2) the increased chloride content of the oedema fluid. 
NUTRITIONAL OEDEMA IN CHILDREN IN EGYPT

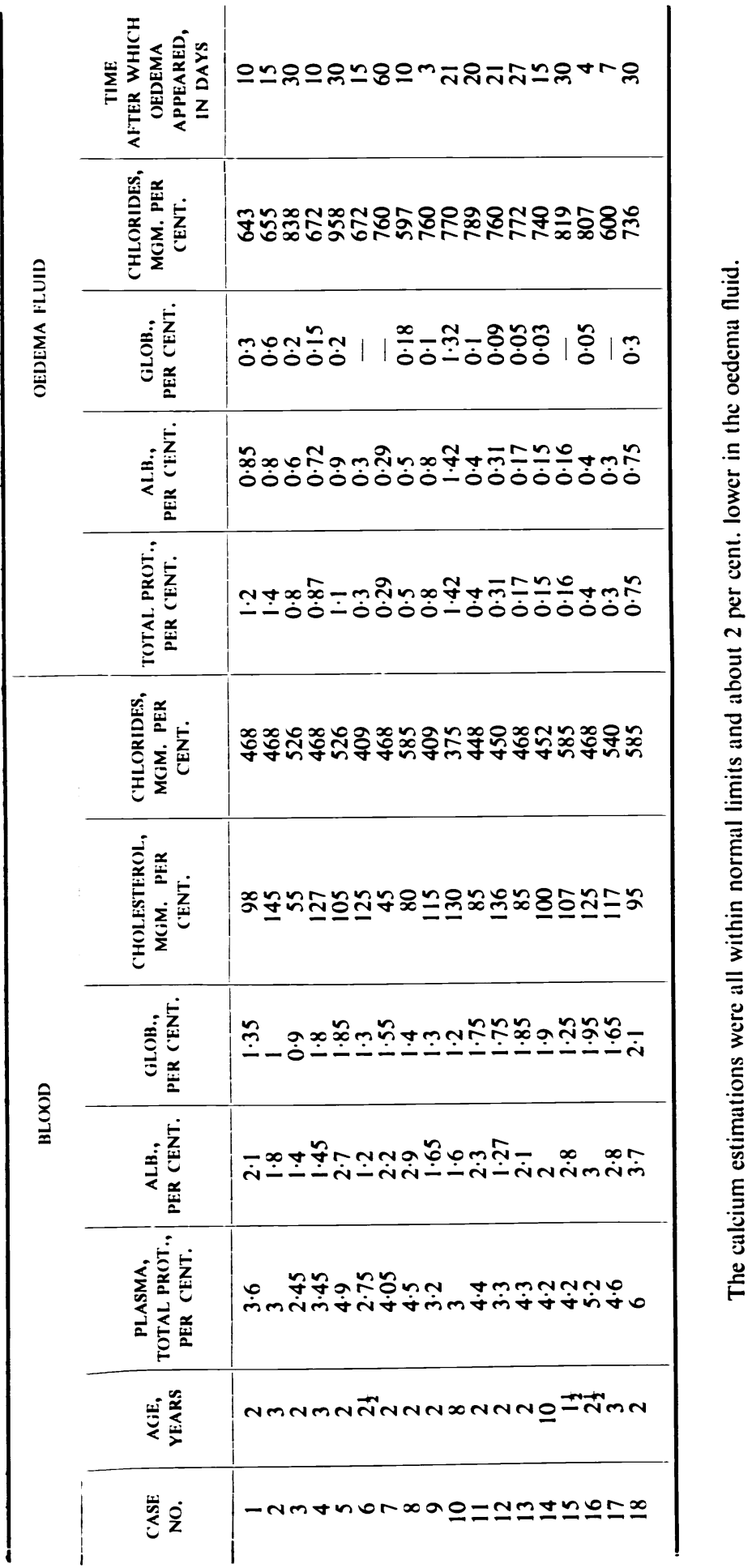




\section{Comments}

Oedema develops whenever the rate of passage of fluid from the capillaries into the tissue spaces exceeds the rate of its absorption by the lymphatics. This occurs when there is :

(1) Lowered effective colloid osmotic pressure of the plasma, i.e. when the colloid osmotic pressure of the plasma becomes less than that of the cellular fluid ;

(2) increased permeability of capillary endothelium to salt and water ; and

(3) abnormal mechanical forces.

1. Since a solution containing $9 \mathrm{gm}$. of sodium chloride per litre is isotonic with the blood serum it follows that the serum chlorides (which are present to the extent of 4.5 to $5.5 \mathrm{gm}$. per litre of blood) contributes about two-thirds of the osmotic pressure of the blood. The remaining one-third is contributed by the bicarbonate and the proteins in the proportion of 3 to 2 . Though oedema fluid and transudates are in approximate diffusion equilibrium with blood plasma, the chloride concentrations in the former are a few per cent. higher. The lower chloride content of the plasma is compensated for by its higher protein concentration. This balance of osmotic forces is liable to variations, due either to the diminution of plasma protein inside the capillaries or to its increase in the tissue spaces as in cases of cardiac failure (Smith, 1937) or to local inflammation. Although the plasma crystalloids have a much higher osmotic value $(5,000-6,000 \mathrm{~mm}$. of mercury) than that of proteins ( $30 \mathrm{~mm}$. of mercury), yet these crystalloids are of little primary influence upon the fluid distribution, as they can easily pass through capillaries. The normal tendency of diffusion in capillaries were the proteins to be diminished or absent would be for the water to pass out under the influence of blood pressure. The restraining influence of the oncotic pressure of the plasma proteins is essential for the normal distribution of fluids in the body. The marked effect of the plasma protein upon the distribution of fluids in the body has been well shown by Weech, Goettsch and Reeves (1935) on dogs. They proved that in feeding dogs on protein-poor diets they could reduce the serum albumin (Weech and Liny, 1931) (serum globulin is not similarly affected) and produce oedema. Though tissue metabolism helps to limit this protein loss in dogs and man (Lin, Chu, Wany and Chung, 1932), yet on prolonged feeding from one to three months on such a diet the plasma albumin could be reduced to the critical level of oedema formation. They also showed that during recovery by feeding on protein-adequate diets if no marked weakness and loss of vitality had occurred, the rise in serum albumin can be rapid. When the experiment was prolonged to a critical point with marked weakness and severe anorexia, recovery was much more tedious, and careful feeding by gavage on milk and casein, lean meat or liver, and stimulating the appetite by feeding on bread and vegetables were found necessary. A rise of serum protein was usually obtained, in some slowly, in others more rapidly, but not always associated with improvement in the general condition. The same authors also showed that prolonged protein deprivation in dogs produced histological and symptomatic evidence of liver 
damage. It is thus possible that return of serum protein to normal levels is determined not only by adequate diet but also by the time required to restore physiological normality of the liver and other tissues concerned with protein synthesis.

The lowered effective osmotic pressure of the plasma in the investigated cases is evident from the table published above in the marked degree of hypoproteinaemia. It was also noticed in this series of cases, as in the dog experiments mentioned above, that though the oedema disappeared within one or two weeks, yet improvement in appetite and blood picture was slow. Enlargement of the liver with marked pallor and cellular changes were seen post mortem in some of the cases.

2. The increased permeability of the capillary endothelium to salt and water is shown in the marked increase of oedema fluid chlorides. These are normally only about $50 \mathrm{mgm}$. per cent. higher in the tissue fluids than in the blood, but in the series of cases investigated the difference was always above $120 \mathrm{mgm}$. per cent. There was rarely any reduction in the serum chlorides, as patients usually received sufficient salts in their diets. In two cases (no. 9 and 16) oedema appeared rapidly in three and four days respectively. Though the duration of the gastro-intestinal disorder was short, yet the previous state of nutrition was poor and the imposed starvation due to the intestinal disease did not require a long time to tip the balance in favour of oedema.

3. Except for gravitation causing an increased local venous pressure, mechanical forces have little effect. Muscular movement lowers the local venous pressure considerably below the level at rest. Any illness reducing muscular activity will increase local venous stasis and pressure and help in the production of oedema.

\section{Summary}

Eighteen cases of gastro-intestinal disorder with oedema, of which three had also tuberculosis of chest and otitis media, were collected. They all showed on investigation a marked hypochromic anaemia, hypoproteinaemia, lowered cholesterol in the blood and a rise in the chloride content of the oedema fluid. This picture is similar to the starvation oedema of animal experiment. The prolonged starvation produces profound metabolic change associated with marked hypoproteinaemia and chloride retention in the tissues. Marked liver damage is often noticed post mortem, suggesting that the rôle it plays in the protein metabolism may be also disturbed.

\section{REFERENCES}

Lin, S. H., Chu, H. I., Wany, S. H., and Chung, H. L. (1932). Chinese J. Physiol., 1, 73. Maver, M. B. (1920). J. Amer. med. Assoc., 74, 934.

Peters, J. P., and Van Slyke, D. (1931). Quantitative Clinical Chemistry, 656.

Smirk, F. H. (1937). Proc. of Kasr-El-Aini Clin. Soc., 7.

Weech, A. A., and Liny, S. M. (1931). J. Clin Invest., 10, 869.

-, Suelling, C. E., and Goettsch, E. (1933). J. Clin. Invest., 12, 193.

Goettsch, E., and Reeves, E. B. (1935). J. Exp. m:1., 61, 299. 